\title{
Article \\ Characterization of Beekeepers and Their Activities in Seven European Countries
}

\author{
Raquel P. F. Guiné ${ }^{1,2, *} \mathbb{0}$, Sónia Mesquita ${ }^{1, *}$, Jorge Oliveira ${ }^{1,2}{ }^{4}$, Catarina Coelho ${ }^{1,3}$, Daniela Teixeira Costa ${ }^{1,2}$, \\ Paula Correia 1,2®], Helena Esteves Correia ${ }^{1,2} \mathbb{1}$, Bjørn Dahle ${ }^{4}$, Melissa Oddie ${ }^{4}$, Risto Raimets ${ }^{5}$, Reet Karise ${ }^{5}$, \\ Luis Tourino ${ }^{6}$, Salvatore Basile ${ }^{7}$, Emilio Buonomo ${ }^{7}$, Ivan Stefanic ${ }^{8}$ and Cristina A. Costa ${ }^{1,2}{ }^{10}$
}

1 Agrarian School of Viseu, Polytechnic Institute of Viseu, 3500-606 Viseu, Portugal; joliveira@esav.ipv.pt (J.O.); ccoelho@esav.ipv.pt (C.C.); daniela@esav.ipv.pt (D.T.C.); paulacorreia@esav.ipv.pt (P.C.); hecorreia@esav.ipv.pt (H.E.C.); amarocosta@esav.ipv.pt (C.A.C.)

2 CERNAS Research Centre, Polytechnic Institute of Viseu, 3504-510 Viseu, Portugal

3 CECAV, Animal and Veterinary Research Center, University of Trás-os-Montes and Alto Douro, 5000-801 Vila Real, Portugal

4 Norwegian Beekeepers Association, 2040 Kløfta, Norway; bjorn.dahle@norbi.no (B.D.); melissa.oddie@nordi.no (M.O.)

5 Institute of Agricultural and Environmental Sciences, Estonian University of Life Sciences, 51014 Tartu, Estonia; ristorai@gmail.com (R.R.); reet.karise@emu.ee (R.K.)

6 Eosa Estrategia y Organización SA, 36202 Vigo, Spain; ltourino@eosa.com

7 Bio-Distretto Cilento, 84052 Ceraso, Italy; presidente@ecoregions.eu (S.B.); emiliobuonomo@gmail.com (E.B.)

8 Tera Tehnopolis, 31000 Osijek, Croatia; istefanic@fazos.hr

* Correspondence: raquelguine@esav.ipv.pt (R.P.F.G.); soniasmmsa@gmail.com (S.M.)

check for updates

Citation: Guiné, R.P.F.; Mesquita, S.; Oliveira, J.; Coelho, C.; Costa, D.T.; Correia, P.; Correia, H.E.; Dahle, B.; Oddie, M.; Raimets, R.; et al.

Characterization of Beekeepers and Their Activities in Seven European Countries. Agronomy 2021, 11, 2398 https://doi.org/10.3390/ agronomy11122398

Academic Editor: Christos Athanassiou

Received: 13 October 2021

Accepted: 22 November 2021

Published: 25 November 2021

Publisher's Note: MDPI stays neutral with regard to jurisdictional claims in published maps and institutional affiliations.

Copyright: (c) 2021 by the authors. Licensee MDPI, Basel, Switzerland. This article is an open access article distributed under the terms and conditions of the Creative Commons Attribution (CC BY) license (https:/ / creativecommons.org/licenses/by/ $4.0 /)$.

\begin{abstract}
Beekeeping is an ancient activity that is gaining interest among practitioners and society in general. It is as an activity with positive impacts in the environmental, social and economic spheres, with the potential to reconnect these dimensions and contribute to sustainable development. Thus, it is important to determine the profiles of beekeepers across the world, and to understand the main social, economic or ecological drivers that shape their activities. Hofstede cross-cultural dimensions were used to better explain differences between countries. A survey was undertaken of beekeepers in different countries (Croatia, Estonia, Finland, Italy, Norway, Portugal, and Spain) in the native language of each nation. A total of 313 questionnaires, using an online platform or in paper form, was delivered face-toface during training or dissemination events in 2019. Norway and Finland were the countries with the highest percentage of respondents with a university degree ( $>80 \%)$, while Spain $(42 \%)$ and Croatia $(48 \%)$ presented the lowest percentages. Most participants were experienced beekeepers $(59 \%$ had more than five years of experience) with more than 50 colonies. With the exception of Italy, beekeeping appears to be a hobby or an additional professional activity. The main beekeeping products for these beekeepers were honey, wax, colonies and propolis, with an average honey production per season of $24.5 \mathrm{~kg} / \mathrm{hive}$. Crossing socio-demographic characteristics and Hofstede cross-cultural dimensions showed a relation among countries with higher Power Distance Index (PDI; this value expresses how society accepts and expects a certain inequality of power) and lower annual income and educational level (Croatia, Portugal, and Spain). A strong correlation appeared between Masculinity Femininity Index (MFI; this value refers to gender effects in society, with feminine societies meaning that the dominant values are caring for others and quality of life, as opposed to masculine societies, which are driven by competition, achievement and success) and age, income and education, with Norway presenting the most feminine society, with more educated and older beekeepers. The Uncertainty Aversion Index (UAI; this value explains how members of a society feel when dealing with unknown situations) was strongly associated with education. The results showed that increasing beekeepers' income will contribute to balancing the distribution of power among members of society, and that this might be achieved by training, especially in Croatia, Portugal, Spain, and Italy.
\end{abstract}

Keywords: beekeeper; bee products; beekeeping sector; Hofstede dimensions 


\section{Introduction}

Although several insect species play a significant role in pollination, honeybees are the most important managed pollinators, not only for agricultural crops but also for wild plants. Hence, managed honeybee colonies impact ecology and the economy to a great extent [1]. Beekeeping activities are ancient, dating back to $4500 \mathrm{BC}$, although nowadays, native beekeeping is complemented with professional, high knowledge input regarding colony management and the production of bee products [2,3].

Beekeeping is as an activity with positive impacts in the environmental, social and economic spheres, playing an extremely important role within family farming. It can also generate extra income or create job opportunities [4]. In many countries, beekeeping activities are transmitted from generation to generation. Uchiyama et al. [2] reported that beekeepers whose knowledge was transmitted from their ancestors tend to have more bee colonies, and also seem to better understand how ecological conditions are fundamental to sustainable beekeeping. Nevertheless, from the 1850s, owing to advances in apicultural science and new technologies, beekeeping became more efficient and profitable, rapidly shifting from family businesses to a commercial activity [5]. The importance of the traditional aspects associated with beekeeping is different among societies and countries [2,6,7], and, in many cases, reflects specific cultural factors [8,9].

Due to the actions focused on economic expansion, we have witnessed a growing imbalance in the social and environmental spheres. Therefore, humanity is faced with a problem that urgently needs to be solved: reconciling the economic dimension with the social and environmental dimensions [10]. The term Sustainability, according to the United Nations (1987), is defined as the ability "to satisfy the needs of the present without compromising the ability of future generations to satisfy their own needs". In this context, beekeeping satisfies all the necessary requirements for sustainability, having a direct relationship with plant biodiversity through pollination [11], as well as showing a capacity to increase the productivity of the primary sector, diversify and stimulate agricultural production, reduce unemployment and promote economic development.

About $35 \%$ of the plants used for human consumption depend on pollination, so the importance of preserving bees as pollinators is undeniable [12]. Three out of four crops that produce fruit or seeds for human consumption depend on pollinators, i.e., largely on bees. In view of the decline of pollinators, Food and Agriculture Organization of the United Nations (FAO) has developed initiatives to promote favorable practices in agricultural management, such as technical assistance to countries regarding the breeding of queen bees and sustainable solutions for the production and marketing of honey [13].

Thus, it is important to determine the profiles of beekeepers across the world, in terms of social, economic or ecological drivers, as well as the difficulties they experience, and to provide them with training on sustainable beekeeping practices to increase and encourage the practice of this activity that is so important for maintaining the balance of ecosystems and for sustainability.

According to Geert Hofstede, discrepancies in behaviors among countries can be attributed to cultural differences $[14,15]$. Hence, it is to be expected that different ways of interpreting, interacting, thinking or behaving might be related to cultural variances. These differences may also be present when someone interacts with people from other subcultures, as well as from different social classes, religions, gender or even from different regions within the same country. In an attempt to explain why people from other cultures seem to behave and think differently, Hofstede developed a theory based on studies he carried out in the 1980s involving more than 50 national cultures. His "Theory of Cultural Dimensions" offers a framework to examine how cultural values affect behaviors and give clues about the ways in which people in a certain cultural environment can act. According to his theory, six cultural dimensions exist: Power Distance Index (PDI); Individualism versus Collectivism Index (ICI); Masculinity versus Femininity Index (MFI); Uncertainty Avoidance Index (UAI); Term Orientation Index (TOI); and Indulgence Restraint Index (IRI) $[14,15]$. Hofstede provided scores for these variables in a number of countries which 
have been used in many fields. For example, they were used to examine cultural differences in the food sector $[16,17]$, in tourism related activities $[18,19]$ and in teaching and learning contexts $[20,21]$.

Given the importance of beekeepers in the European Union, in particular nonprofessional and family beekeepers, it is relevant to understand how beekeeping activities develop in different socio-economic and cultural contexts, as a first step to sharing experiences across contexts in order to promote international cooperation, beekeeping innovation and the exchange of good practices. In this context, the aim of this research is to understand how socio-economic and cultural dimensions influence beekeepers' options and contribute to more sustainable practices. To this end, we first characterize beekeeping activities in seven European countries, and then investigate possible differences according to sociodemographic variables and variables characterizing beekeeping activities. Finally, we relate these variables with the cross-cultural dimensions defined by Hofstede.

\section{Materials and Methods}

The survey was sent to beekeepers in different countries as a part of the Beeb-beekeeping bridges project (2019-1-PT01-KA202-060782). The questionnaire was divided into different sections as follows: (I) Experience in beekeeping (comprising 10 questions); (II) Training needs (3 questions); (III) Experience in beekeeping training activities (3 questions); (IV) Use of distance learning technologies and tools (3 questions); (V) Distance learning tools (4 questions); and (VI) Sociodemographic characterization (6 questions). In this manuscript, parts (I) and (VI) of the questionnaire are addressed.

The questionnaire was translated into the languages of the different countries in which it was applied, i.e., Croatia, Estonia, Finland, Italy, Norway, Portugal, and Spain (Figure 1). The questionnaire, using an online platform or in paper, was delivered face-to-face during training or dissemination events organized by beekeeper associations or companies in each country.

For data treatment, the SPSS version 26 and Excel 2016 software were used. Basic statistical tools were utilized to describe the data, such as frequencies or mean values. To evaluate possible differences between the variables characterizing beekeeping activities among countries, crosstabs with chi-square tests were performed. The Cramer's V coefficient was considered when evaluating the strength of the relations between some of the variables under study. This coefficient varies from 0 to 1 ; for $\mathrm{V} \approx 0.1$, the association was considered weak, while for $\mathrm{V} \approx 0.3$ and $\mathrm{V} \approx 0.5$ or over, the association was moderate and strong, respectively [22].

The obtained values for Hofstede's cross-cultural dimensions are shown in Table 1. Spearman correlations were determined in order to assess the relations between the six Hofstede cross-cultural dimensions and some other variables (sociodemographic variables and variables characterizing beekeeping activities). To this end, mean values of the tested variables were determined for each country (for ratio variables, i.e., age, income, time of activity, number of colonies, relevance of the activity) or percentage of positive responses (for categorical variables, i.e., being male, being a beekeeper, a technician, or a merchant, no one working on beekeeping project, family, friends, hired people).

The strength of the correlations was evaluated according to the following limits: if $\rho=0$, there is no correlation; if $\rho \in[0.0,0.2]$ the correlation is very weak; if $\rho \in[0.2,0.4]$, the correlation is weak; if $\rho \in[0.4,0.6]$, the correlation is moderate; if $\rho \in[0.6,0.8]$, the correlation is strong; if $\rho \in[0.8,1.0]$, the correlation is very strong; and if $\rho=1$, the correlation is perfect $[23,24]$. The level of significance was 0.05 in all cases. 

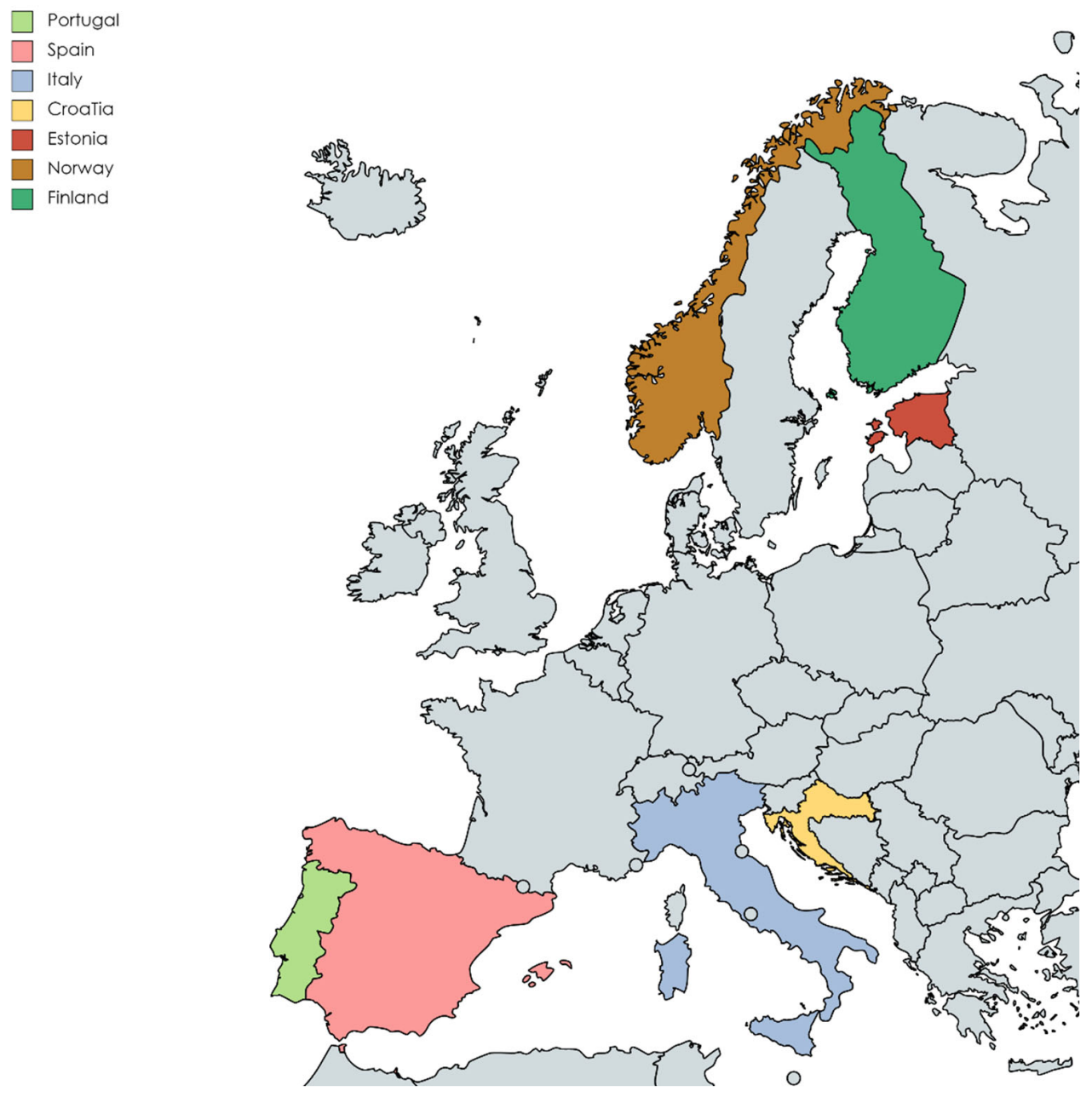

Figure 1. Geographical location of the countries included in the study.

Table 1. Scores of predictor variables (Hofstede's cross-cultural dimensions) for the seven countries included in the study [25].

\begin{tabular}{ccccccc}
\hline Country & PDI & ICI & MFI & UAI & TOI & IRI \\
\hline Croatia & 73 & 33 & 40 & 80 & 58 & 33 \\
Estonia & 40 & 60 & 30 & 60 & 82 & 16 \\
Finland & 33 & 63 & 26 & 59 & 38 & 57 \\
Italy & 50 & 76 & 70 & 75 & 61 & 30 \\
Norway & 31 & 69 & 8 & 50 & 35 & 55 \\
Portugal & 63 & 27 & 31 & 99 & 28 & 33 \\
Spain & 57 & 51 & 42 & 86 & 48 & 44 \\
\hline
\end{tabular}

Legend: Hofstede's cross-cultural dimensions: PDI—Power Distance Index; ICI—Individualism Collectivism Index; MFI-Masculinity—Femininity Index; UAI—Uncertainty Avoidance Index; TOI—Term Orientation Index IRI-Indulgence Restraint Index. "Rule of the thumb"-If a score was under 48, the cultural score was relatively low on that scale, while if a score was over 52 , the cultural scores were high on that scale. Scores between 48 and

52 were considered as intermediate. $\square$ high; $\square$ intermediate; $\square$ low.

\section{Results}

\subsection{Sample Characterization}

Table 2 shows a sociodemographic characterization of the sample, which consisted of 313 participants from the seven countries included in the study. Norway was the country where most responses were collected $(n=74)$, followed by Croatia $(n=64)$, while those with the fewest responses were Finland and Italy ( $n=15$ and $n=16$, respectively). 
Table 2. Sociodemographic characterization of the sample $(\mathrm{N}=313)$.

\begin{tabular}{|c|c|c|c|}
\hline Variables & Categories & $n$ & $\%$ \\
\hline \multirow{7}{*}{ Country } & Portugal & 48 & 15.3 \\
\hline & Estonia & 44 & 14.1 \\
\hline & Norway & 74 & 23.6 \\
\hline & Spain & 52 & 16.6 \\
\hline & Italy & 16 & 5.1 \\
\hline & Croatia & 64 & 20.4 \\
\hline & Finland & 15 & 4.8 \\
\hline \multirow{4}{*}{ Age } & Young (up to $30 \mathrm{y}$ ) & 29 & 9.3 \\
\hline & Middle aged ( $31-59$ y) & 212 & 67.7 \\
\hline & Senior (age 60 or more) & 57 & 18.2 \\
\hline & No answer & 15 & 4.8 \\
\hline \multirow{3}{*}{ Sex } & Female & 73 & 23.3 \\
\hline & Male & 231 & 73.8 \\
\hline & No answer & 9 & 2.9 \\
\hline \multirow{4}{*}{ Education } & Basic & 10 & 3.2 \\
\hline & Secondary & 110 & 35.1 \\
\hline & University & 183 & 58.5 \\
\hline & No answer & 10 & 3.2 \\
\hline \multirow{4}{*}{ Income } & Less than $15,000 € /$ year & 79 & 25.2 \\
\hline & Between 15,000 to $50,000 € /$ year & 120 & 38.3 \\
\hline & More than $50,000 € /$ year & 71 & 22.7 \\
\hline & No answer & 43 & 13.7 \\
\hline \multirow{3}{*}{ Activity Type } & Beekeeper & 261 & 80.5 \\
\hline & Techician & 39 & 12.0 \\
\hline & Merchant & 24 & 7.4 \\
\hline
\end{tabular}

Regarding age, participants were categorized as follows: young (up to 30 years old), middle-aged (between 31 and 59 years old) and senior (60 years or over). The distribution by age was 29 young respondents, 212 middle-aged respondents and 57 seniors (Table 2). From the 313 participants, 15 did not indicate their age. In terms of country distribution (Figure 2a), Italy was the country with highest percentage of young adults $(31 \%)$, while Norway and Finland had the highest percentages of senior adults (37\% and $29 \%$, respectively).

As for gender, only nine participants did not specify their sex. The results indicated that the sample at study comprised mostly men, i.e., 231, with only 73 women (see Table 2). In Spain, Portugal and Finland, the differences between gender were more pronounced, with only $10 \%, 11 \%$ and $13 \%$ female participants, respectively.

Among the surveyed beekeepers, most had completed a university degree $(n=183)$ or secondary school $(n=110)$; a very low number, i.e., 10 participants, reported the lowest level of education (basic school only). Ten participants failed to respond to this question (Table 2).

Norway and Finland presented the highest percentage $(>80 \%)$ of respondents that had completed a university education (Figure 2b), while Spain and Croatia presented the lowest percentage for this indicator ( $42 \%$ and $48 \%$, respectively). Accordingly, Spain presented the higher percentage for participants who had completed only basic education, i.e., $12 \%$.

Finally, for those who felt comfortable, one question addressed household annual income. For this question, a total of 270 answers were obtained, showing that for most participants $(n=120)$, annual income was between 15,000 and 50,000 $€$ /year (Table 2). About $86 \%$ of participants from Norway had an annual income above 50,000 $€$, while few participants from Italy, Croatia, Spain or Portugal were within the highest income category $(0 \%, 2 \%, 8 \%$ and $9 \%$, respectively). Regarding the lowest annual income, i.e., under $15,000 €$, Italy stood out with the highest percentage (63\%), followed by Croatia (53\%) (Figure 2c). 
The participants were asked if they had beekeeping experience, and, if so, in which role(s), i.e., beekeeper, technician or merchant. The results revealed that participants were mostly beekeepers $(n=261)$, with few respondents identifying as technicians $(n=39)$ or merchants $(n=24)$.

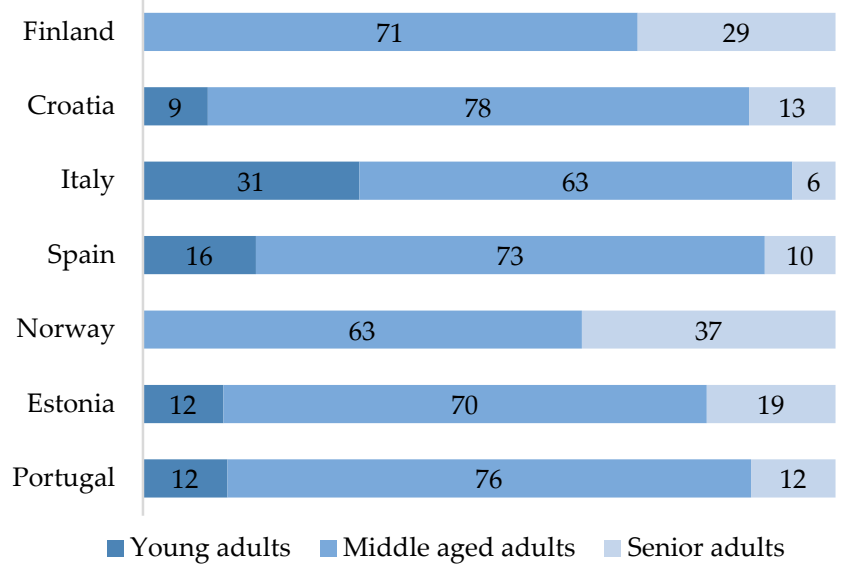

(a)

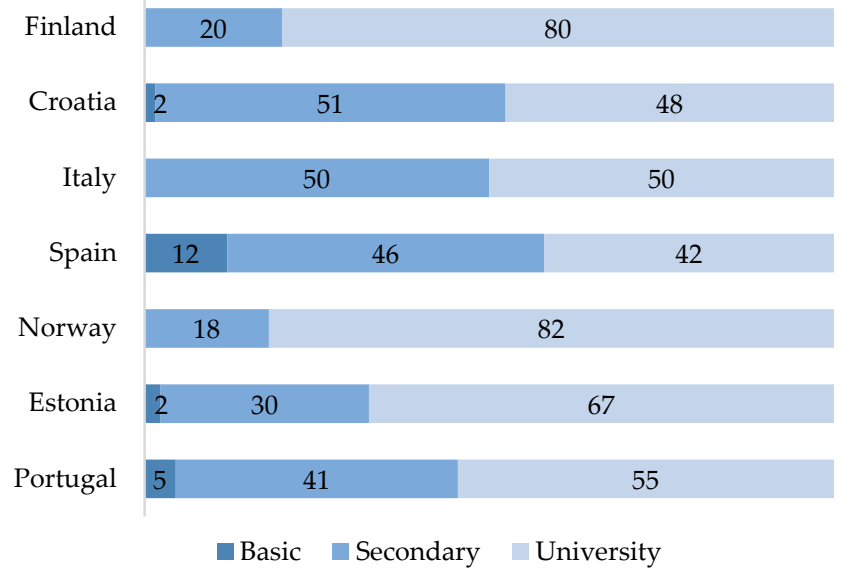

(b)

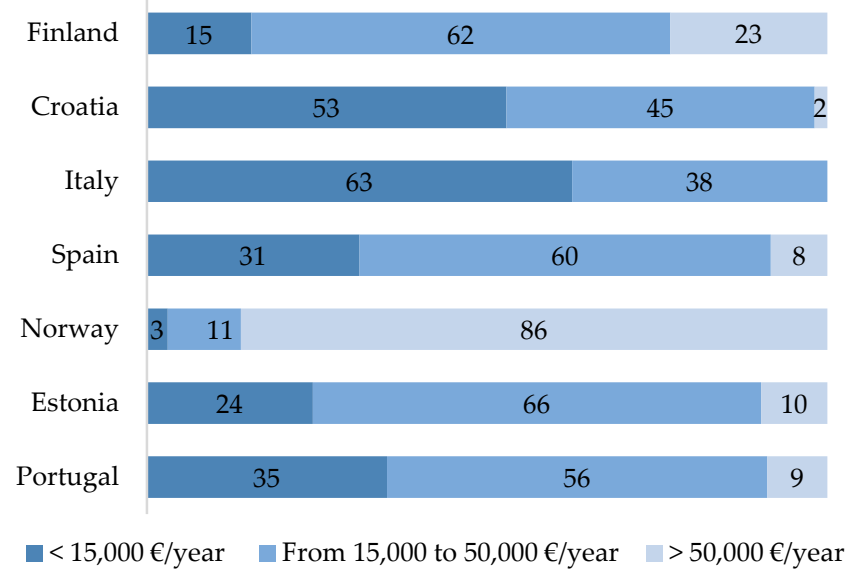

(c)

Figure 2. Relative distribution of age (a), education level (b), and income (c) by country (\%).

\subsection{Characterization of Beekeeping Activity}

Most participants were experienced beekeepers, with only $9 \%$ reporting less than one year of activity, 32\% with between 1 and 5 years of experience, $23 \%$ between 5 and 10 years of experience, and 36\% reporting having worked in the field for more than 10 years. Twenty-six participants did not respond to this question. In Italy, the percentage of beekeepers with more than 10 years or experience was low $(8 \%)$; Finland and Croatia reported the highest numbers of beekeepers with more than 10 years of experience $(47 \%$ and $42 \%$, respectively) (Figure 3 ).

The number of honeybee colonies per participant was highly variable, up to a maximum of 2400 , distributed follows: up to 50 colonies $(n=178)$, between 51 and $150(n=56)$, between 151 and $300(n=21)$ and more than $301(n=17)$. From the 272 participants who indicated the number of colonies, the majority had a low number $(65 \%)$. The result analyzed by country showed a similar trend, with participants being mostly beekeepers with stocks of up to 50 colonies (varying from $43 \%$ to $82 \%$ ). This percentage was lowest for Finland. In contrast, Portugal had the highest percentage of beekeepers with 301 or more colonies (23\%) (Figure 4). 


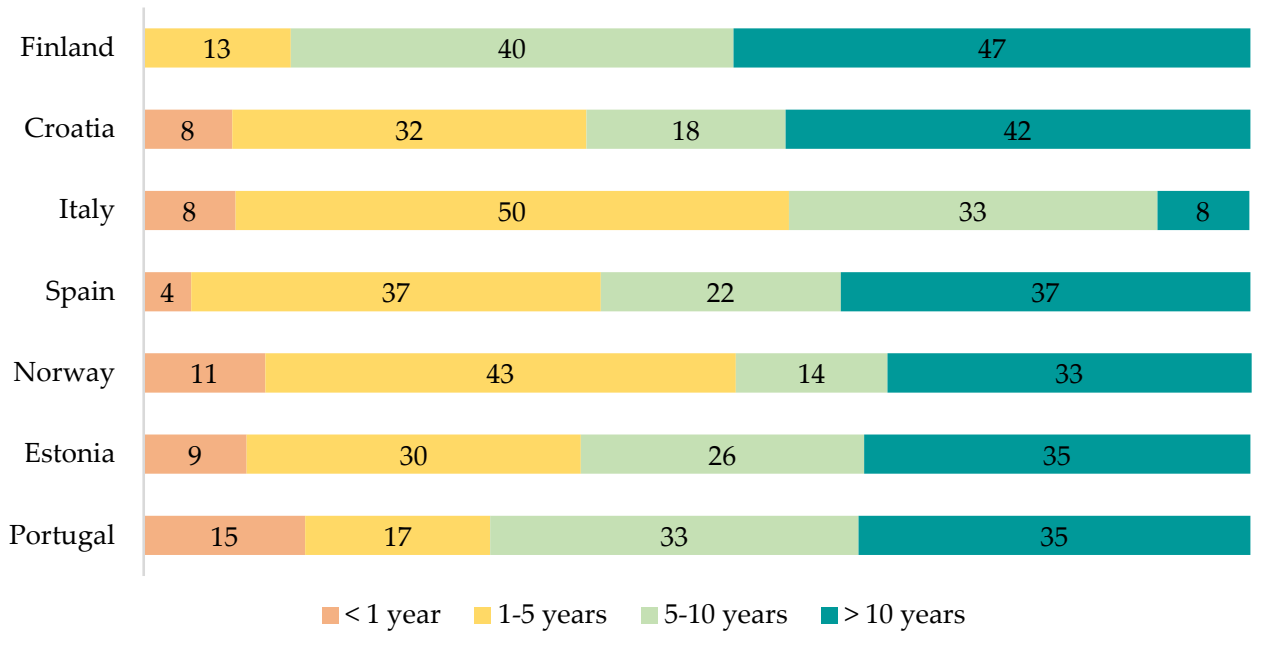

Figure 3. Relative distribution of time of activity by country (\%).

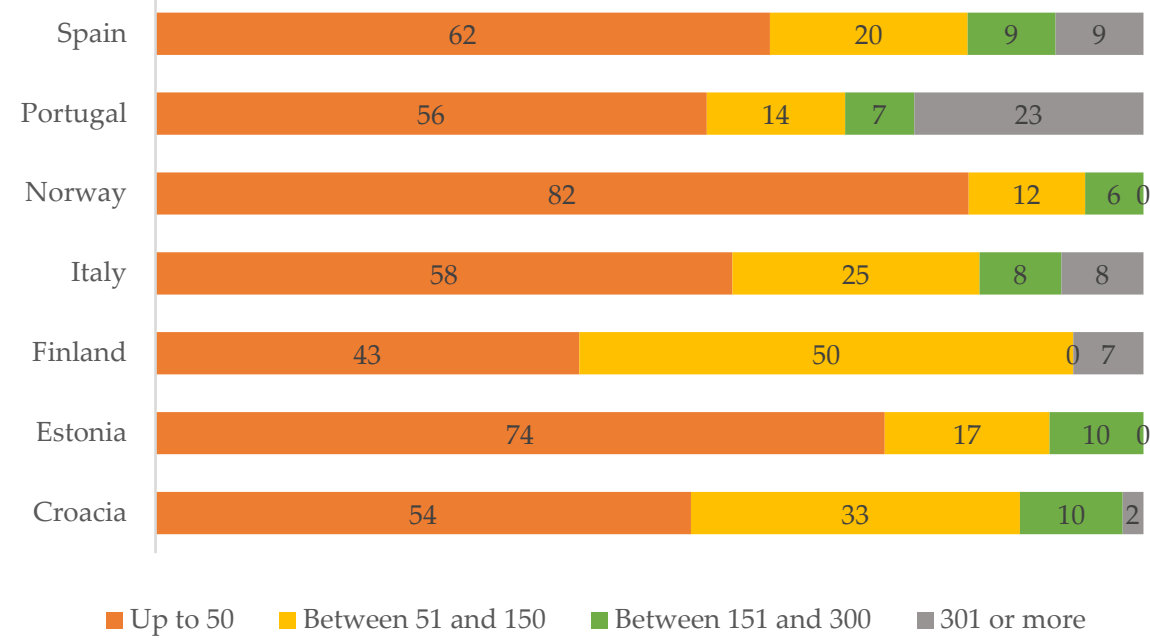

Figure 4. Relative distribution of number of honeybee colonies by country (\%).

When asked about the relevance of the beekeeping activities, some said it was a hobby (120 participants), and as such, the products were mainly for self-consumption, family and gifts. Others said that it was a source of additional income for the family (118 participants). Finally, it was reported as a core business for a small number of participants, i.e., 43 participants, representing 15\%. With the exception of Italy, where the majority (42\%) cited beekeeping as their main source of income, in all countries, the prevailing trend was that beekeeping was a hobby or an additional source of income (Figure 5a).

In most cases $(n=217)$, all the work involved in the beekeeping activity was done by the individual, with help from unpaid collaborators. In fact, only a minority of the work was done by people hired specifically for a given job (only $2 \%$ of the beekeepers reported hiring workers). Family members or friends frequently participated, as reported by $49 \%$ and $9 \%$ of participants, respectively. A large number of participants revealed that they worked alone $(40 \%)$. Figure $5 \mathrm{~b}$ shows the relative importance of these stakeholders in beekeeping activities by country. The roles of the beekeepers and their families were shown to be pivotal in all countries, collectively representing a minimum of $79 \%$ in Spain and a maximum of $100 \%$ in Estonia. Italy was the country with the highest percentage of hired people, even though this still only represented $17 \%$.

The participants were also asked to indicate the three most important products in their beekeeping activities; the results are presented in Table 3. The global results showed that the most important products were honey (285 positive answers), wax (103) and colonies (87). 
Propolis ranked fourth, very close to colonies, being indicated by 82 participants as one of the three most important products in their beekeeping activities.

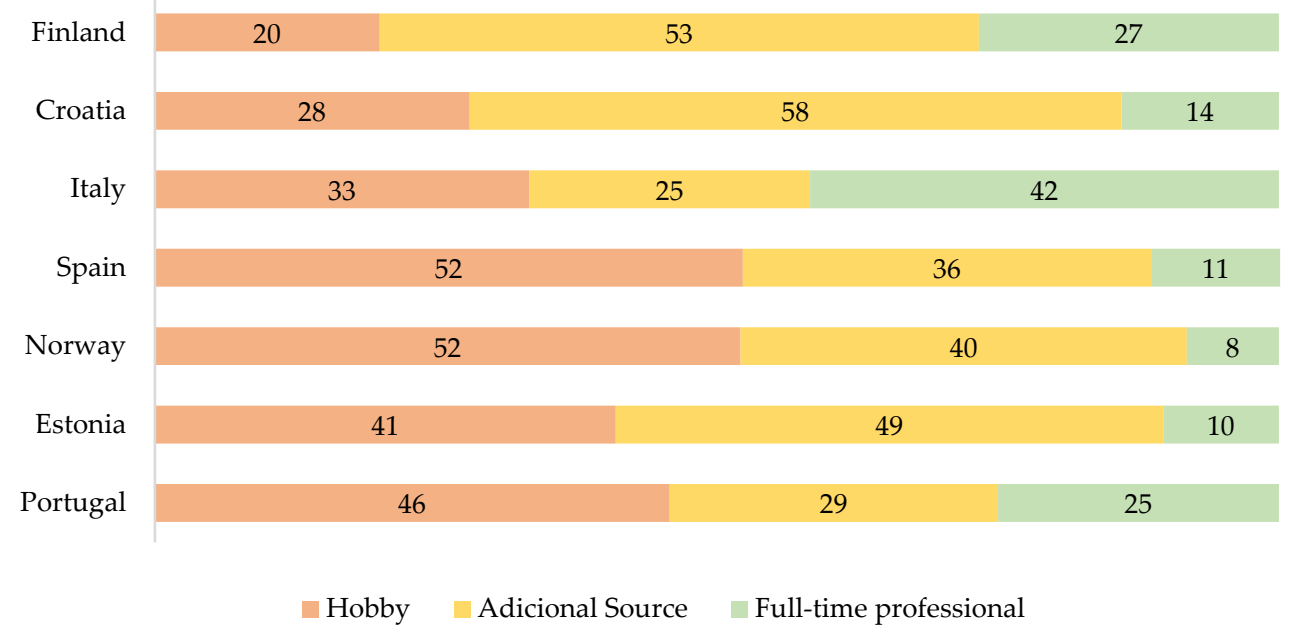

(a)

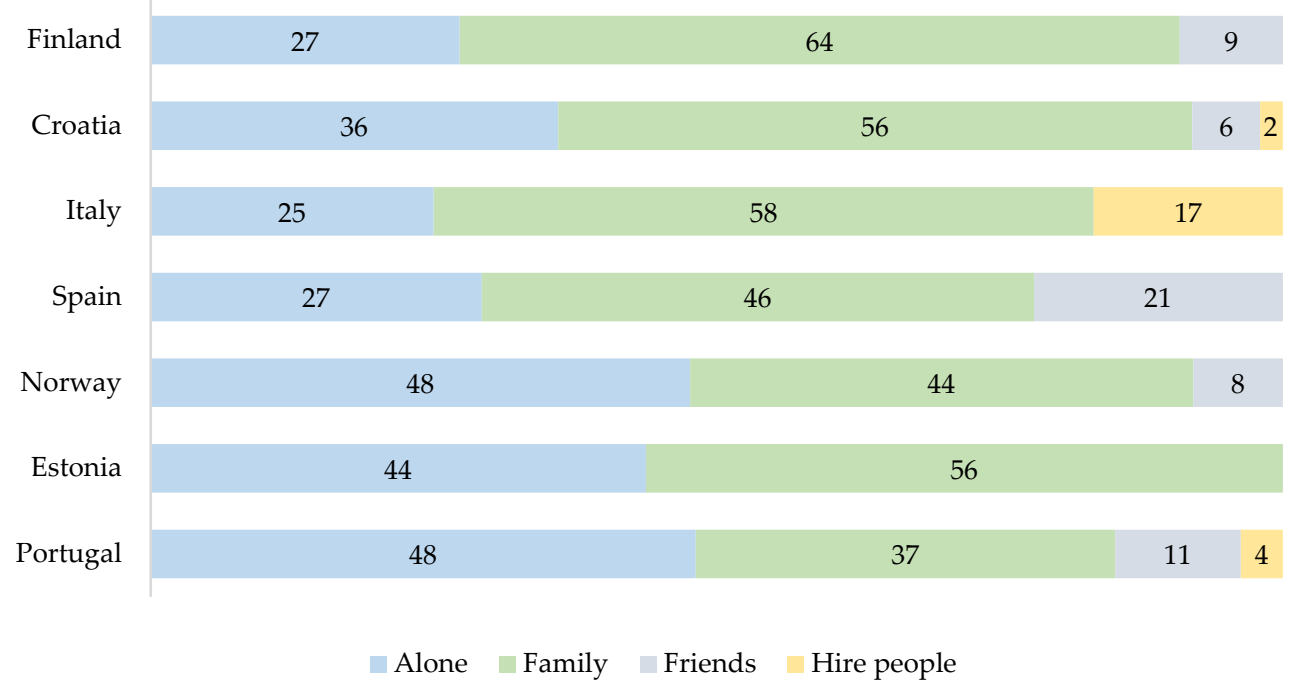

(b)

Figure 5. Relative distribution of the beekeeping activity relevance (a) and people who work in beekeeping by country $(\mathbf{b})(\%)$.

Table 3. Relevant products of beekeeping activities by country (Results presented as number of beekeepers).

\begin{tabular}{|c|c|c|c|c|c|c|c|c|}
\hline & $\begin{array}{l}\text { Portugal } \\
(\mathrm{N}=48)\end{array}$ & $\begin{array}{l}\text { Estonia } \\
(\mathrm{N}=44)\end{array}$ & $\begin{array}{l}\text { Norway } \\
(\mathrm{N}=74)\end{array}$ & $\begin{array}{c}\text { Spain } \\
(\mathrm{N}=52)\end{array}$ & $\begin{array}{c}\text { Italy } \\
(N=16)\end{array}$ & $\begin{array}{r}\text { Croatia } \\
(\mathrm{N}=64)\end{array}$ & $\begin{array}{l}\text { Finland } \\
(N=15)\end{array}$ & Total \\
\hline Honey & 46 & 43 & 69 & 50 & 12 & 51 & 14 & 285 \\
\hline Wax & 19 & 20 & 29 & 8 & 4 & 20 & 3 & 103 \\
\hline Colonies & 15 & 10 & 24 & 15 & 2 & 17 & 4 & 87 \\
\hline Propolis & 10 & 17 & 2 & 11 & 10 & 27 & 5 & 82 \\
\hline Polen & 10 & 5 & 4 & 10 & 7 & 19 & 4 & 59 \\
\hline Queens & 5 & 8 & 29 & 7 & 2 & 2 & 3 & 56 \\
\hline Polination services & 8 & 1 & 8 & 4 & 0 & 3 & 3 & 27 \\
\hline Royal gelee & 0 & 1 & 0 & 1 & 0 & 6 & 0 & 8 \\
\hline Apitoxin & 0 & 0 & 0 & 2 & 0 & 1 & 0 & 3 \\
\hline
\end{tabular}


From the participants in the survey, 92 indicated that they were migratory beekeepers while 194 were not. As for the mode of production, 74 declared themselves to be organic producers compared to 214 who were not. Among those who were organic, only 16 were certified.

The participants were asked about the average honey production per hive, considering the last season; the obtained responses were highly variable. The results for honey production per hive were classified as follows: $0 \mathrm{~kg}(n=14) ; 1-10 \mathrm{~kg}(n=44) ; 11-20 \mathrm{~kg}(n=78)$; $21-50 \mathrm{~kg}(n=95) ; 51-100 \mathrm{~kg}(n=18) ;$ and greater than $100 \mathrm{~kg}$ (only one producer). In most cases, honey production between 21 and $50 \mathrm{~kg}$ per hive per season was reported. The results showed that the average honey production per hive by country was, in decreasing order, $38 \mathrm{~kg}$ in Estonia, $36 \mathrm{~kg}$ in Finland, $13.7 \mathrm{~kg}$ in Portugal, $32 \mathrm{~kg}$ in Croatia, $27 \mathrm{~kg}$ in Norway, $19 \mathrm{~kg}$ in Spain and $17 \mathrm{~kg}$ in Italy.

\subsection{Country Differences in the Beekeeping Activity}

Table 4 shows the relations between country for additional variables. Significant differences were observed for beekeeper age among countries $(p<0.0012)$, and the association was moderate $(\mathrm{V}=0.456)$. Italy $(36.25 \%)$ was the country with the highest number of young adults, followed by Spain (16.3\%). In Croatia (78.1\%), Portugal $(75.6 \%)$ and Spain $(73.5 \%)$, middle-aged adults represented the majority. Gender was significantly different among countries $(p=0.006)$, with a moderate association between variables $(\mathrm{V}=0.244)$. The highest percentage of women beekeepers was reported in Italy (37.5\%), followed by Estonia $(35.7 \%)$. Income differences between countries were highly significant $(p<0.0000)$ and the association was strong $(\mathrm{V}=0.573)$. Norwegian beekeepers had the highest income.

Table 4. Crosstabs and Chi-square tests among countries and some sociodemographic variables and variables associated with beekeeping activities. Percentages of positive answers for each variable.

\begin{tabular}{|c|c|c|c|c|c|c|c|}
\hline Variables/Categories & Croacia & Estonia & Finland & Italy & Norway & Portugal & Spain \\
\hline \multicolumn{8}{|l|}{ Age $(p<0.012, \mathrm{~V}=0.456)^{(1)}$} \\
\hline Young (up to $30 \mathrm{y}$ ) & 9.4 & 11.6 & 0.0 & 31.25 & 0.0 & 12.2 & 16.3 \\
\hline Middle age (31-59 y) & 78.1 & 69.8 & 71.4 & 62.5 & 63.4 & 75.6 & 73.5 \\
\hline Senior $(60 \mathrm{y}$ or over) & 12.5 & 18.6 & 28.6 & 6.25 & 36.6 & 12.2 & 10.2 \\
\hline \multicolumn{8}{|l|}{$\operatorname{Sex}(p=0.006, V=0.244)^{(1)}$} \\
\hline Female & 25.0 & 35.7 & 13.3 & 37.5 & 32.9 & 11.4 & 10.0 \\
\hline Male & 75.0 & 64.3 & 86.7 & 62.5 & 67.1 & 88.6 & 90.0 \\
\hline \multicolumn{8}{|l|}{ Education level $(p=0.0000, \mathrm{~V}=0.263)^{(1)}$} \\
\hline Basic & 1.6 & 2.3 & 0.0 & 0.0 & 0.0 & 4.55 & 12.0 \\
\hline Secondary & 50.8 & 30.2 & 20.0 & 50.0 & 18.1 & 40.9 & 46.0 \\
\hline University & 47.6 & 67.5 & 80.0 & 50.0 & 81.9 & 54.55 & 42.0 \\
\hline \multicolumn{8}{|l|}{ Income $(p<0.0000, \mathrm{~V}=0.573)$} \\
\hline Less than $15000 € /$ year & 58.2 & 24.4 & 15.4 & 62.5 & 3.1 & 35.3 & 31.3 \\
\hline 15000 to $50,000 € /$ year & 45.3 & 65.8 & 61.5 & 37.5 & 10.8 & 55.9 & 60.4 \\
\hline More than $50,000 € /$ year & 1.9 & 9.8 & 23.1 & 0.0 & 86.1 & 8.8 & 8.3 \\
\hline \multicolumn{8}{|l|}{ Experience in beekeeping activities } \\
\hline Beekeeper $(p<0.0000, \mathrm{~V}=0.332)^{(1)}$ & 43.8 & 81.2 & 82.3 & 80.0 & 97.4 & 86.8 & 95.7 \\
\hline Beekeeping technician $(p<0.0000, \mathrm{~V}=0.755)$ & 35.9 & 9.4 & 11.8 & 13.3 & 1.3 & 7.5 & 4.3 \\
\hline Beekeeping merchant $(p<0.0000, \mathrm{~V}=0.738)^{(1)}$ & 20.3 & 9.4 & 5.9 & 6.7 & 1.3 & 5.7 & 0.0 \\
\hline \multicolumn{8}{|l|}{ Time of activity $(p=0.112, \mathrm{~V}=0.172)$} \\
\hline Less than 1 year & 8.0 & 9.3 & 0.0 & 8.3 & 10.9 & 14.6 & 4.3 \\
\hline 1 to 5 years & 32.0 & 30.2 & 13.3 & 50.0 & 42.5 & 16.7 & 37.0 \\
\hline 6 to 10 years & 18.0 & 25.6 & 40.0 & 33.4 & 13.7 & 33.3 & 21.7 \\
\hline More than 10 years & 42.0 & 34.9 & 46.7 & 8.3 & 32.9 & 35.4 & 37.0 \\
\hline \multicolumn{8}{|l|}{ Number of colonies $(p<0.000, V=0.249)$} \\
\hline Up to 50 & 54.2 & 73.8 & 42.9 & 58.4 & 82.3 & 55.8 & 62.2 \\
\hline Between 51 and 150 & 33.3 & 16.7 & 50.0 & 25.0 & 11.8 & 14.0 & 20.0 \\
\hline Between 151 and 300 & 10.4 & 9.5 & 0 & 8.3 & 5.9 & 7.0 & 8.9 \\
\hline 301 or more & 2.1 & 0 & 7.1 & 8.3 & 0 & 23.2 & 8.9 \\
\hline
\end{tabular}


Table 4. Cont.

\begin{tabular}{|c|c|c|c|c|c|c|c|}
\hline Variables/Categories & Croacia & Estonia & Finland & Italy & Norway & Portugal & Spain \\
\hline \multicolumn{8}{|c|}{ Relevance of the beekeeping activity $(p=0.006, \mathrm{~V}=0.221)^{(1)}$} \\
\hline Hobby & 28.0 & 37.2 & 20.0 & 33.3 & 52.1 & 45.8 & 52.2 \\
\hline Source of additional income & 58.0 & 51.2 & 53.3 & 25.0 & 39.7 & 29.2 & 36.4 \\
\hline Main business & 14.0 & 11.6 & 26.7 & 41.7 & 8.2 & 25.0 & 11.4 \\
\hline \multicolumn{8}{|l|}{ People who work in beekeeping } \\
\hline No one $(p=0.305, \mathrm{~V}=0.151)^{(1)}$ & 36.0 & 32.6 & 20.0 & 25.0 & 41.1 & 48.1 & 27.3 \\
\hline Family $(p=0.05, \mathrm{~V}=0.197)^{(1)}$ & 56.0 & 55.8 & 46.7 & 58.3 & 45.2 & 37.0 & 47.7 \\
\hline Friends $(p=0.013, V=0.227)^{(1)}$ & 6.0 & 2.3 & 13.3 & 0.0 & 12.3 & 11.1 & 25.0 \\
\hline Hired $(p=0.001, \mathrm{~V}=0.264)$ & 2.0 & 9.3 & 20.0 & 16.7 & 1.4 & 3.7 & 0.0 \\
\hline \multicolumn{8}{|c|}{ Fraction of work done by you, your family or unpaid friend/neigbours $(p=0.0000, \mathrm{~V}=0.264){ }^{(1)}$} \\
\hline All $(100 \%)$ & 93.9 & 83.3 & 50.0 & 83.3 & 94.4 & 55.6 & 81.8 \\
\hline More than $50 \%$ & 4.1 & 11.9 & 42.9 & 16.7 & 4.2 & 40.7 & 9.1 \\
\hline Between 25 and $50 \%$ & 0.0 & 0.0 & 7.1 & 0.0 & 0.0 & 3.7 & 2.3 \\
\hline Less than $25 \%$ & 2.0 & 4.8 & 0.0 & 0.0 & 1.4 & 0.0 & 6.8 \\
\hline
\end{tabular}

(1) Chi-square test p-value (level of significance of 0.05) and Cramer's V coefficient.

Regarding experience as a beekeeper, technician or merchant, highly significant differences were found $(p<0.0000)$ in all cases, with a moderate association for beekeeper $(\mathrm{V}=0.332)$ and strong associations for technician $(\mathrm{V}=0.755)$ and merchant $(\mathrm{V}=0.738)$. For the number colonies, differences between countries were significant and moderate $(p<0.000, \mathrm{~V}=0.249)$. The relevance of beekeeping activity was very significantly different between countries $(p=0.006)$, and the association was moderate $(\mathrm{V}=0.221)$. Regarding the types of people who work in beekeeping, significant differences were found between countries where beekeepers reported receiving help from friends $(p=0.013)$, with a moderate association $(\mathrm{V}=0.227)$, and very significant differences were observed for beekeepers who hired personnel $(p=0.001)$, with a moderate association $(\mathrm{V}=0.264)$. Regarding the portion of work done by the beekeeper, family or unpaid friends/neighbors and education level, highly significant differences were found $(p=0.0000)$ among counties with a moderate association ( $\mathrm{V}=0.264$ and $\mathrm{V}=0.263$, respectively). However, for the variable "time of activity", no significant differences were found among countries $(p=0.112)$.

\subsection{The Hofstede's Cross-Cultural Dimensions}

In this work, the relation between some variables and the Hofstede cross-cultural dimensions was also investigated. The values of the six dimensions for the countries in this study are presented in Table 1, while Table 5 shows the associations between the Hofstede cultural dimensions and some other sociodemographic characteristics and beekeeping technical options.

As seen in Table 5, PDI was inversely significantly correlated with income and educational, and the association was very strong $(\rho=-0.786$ and $\rho=-0.865)$. According to our Hofstede analysis, Norway (31\%), Finland (33\%) and Estonia (40\%) were the countries with lowest PDI values (Table 1). These were also the countries where a higher number of beekeepers had more than 50,000 $€$ of annual income (Norway- $86.1 \%$, Finland $-23.1 \%$ and Estonia-9.8\%) and higher educational level (Norway-81.9\%, Finland-80.0\% and Estonia-67.5\%).

Regarding ICI [14], individualist countries were Italy (76\%), Norway (69\%) and Finland $(63 \%)$, while Croatia $(33 \%)$ and Portugal $(27 \%)$ stood out as collectivist countries (Table 1). The results in Table 5 reveal that there were no significant correlations between ICI and the variables studied.

MFI was inversely significantly correlated with age $(\rho=-0.964)$, income $(\rho=-0.893)$ and education level $(\rho=-0.847)$, with a very strong association (Table 5) [14]. Among the seven countries, only one revealed a high level of masculinity, i.e., Italy (70\%) (Table 1). This country presented the lowest rate $(6.25 \%)$ of senior beekeepers (60 years or over), and not a single beekeeper with more than $50,000 €$ of annual income. Regarding educational, $50 \%$ of Italian participants had secondary level and 50\% superior level. 
UAI was significant correlated with the number of colonies $(\rho=0.811)$, and was inversely significantly correlated with educational level $(\rho=-0.847)$ [14]. The countries included in this research showed high UAI. Portugal was the country with the most participants reporting more than 301 colonies (more than $23 \%$ ), but was also the country with the highest percentage (12.0\%) of participants with basic education.

Table 5. Spearman correlations between the Hofstede scores of cultural dimensions and the variables that characterize beekeeping activities and the sociodemographic characteristics of beekeepers.

\begin{tabular}{|c|c|c|c|c|c|c|}
\hline Variables/Categories & PDI & ICI & MFI & UAI & TOI & IRI \\
\hline Sex & 0.357 & -0.679 & 0.000 & 0.536 & -0.607 & 0.541 \\
\hline Age & -0.750 & 0.143 & $-0.964^{* *}$ & -0.643 & -0.464 & 0.541 \\
\hline Income & $-0.786^{*}$ & 0.214 & $-0.893^{* *}$ & -0.679 & -0.357 & 0.595 \\
\hline Education level & $-0.865 *$ & 0.541 & $-0.847^{*}$ & $-0.847 *$ & -0.234 & 0.300 \\
\hline \multicolumn{7}{|l|}{ Experience in beekeeping activities } \\
\hline Beekeeper & -0.464 & 0.036 & -0.464 & -0.143 & -0.679 & 0.577 \\
\hline Beekeeping technician & 0.429 & 0.000 & 0.429 & 0.107 & 0.536 & -0.360 \\
\hline Beekeeping merchant & 0.286 & -0.036 & 0.143 & -0.071 & 0.643 & -0.577 \\
\hline Time of activity & 0.286 & -0.536 & -0.143 & 0.179 & -0.214 & 0.505 \\
\hline Number of colonies & 0.631 & -0.342 & 0.703 & 0.811 * & -0.180 & -0.209 \\
\hline Relevance of the beekeeping activity & 0.250 & 0.179 & 0.429 & 0.107 & 0.286 & -0.198 \\
\hline \multicolumn{7}{|l|}{ People who work in the beekeeping } \\
\hline No one & 0.071 & -0.536 & -0.500 & 0.143 & -0.500 & -0.054 \\
\hline Family & -0.286 & 0.536 & 0.107 & -0.429 & 0.607 & -0.054 \\
\hline Friends & 0.162 & -0.487 & -0.072 & 0.414 & -0.739 & 0.655 \\
\hline Hired & 0.571 & -0.079 & 0.630 & 0.512 & 0.039 & -0.477 \\
\hline
\end{tabular}

Hofstede's cross-cultural dimensions: PDI—Power Distance Index; ICI—Individualism Collectivism Index; MFI—Masculinity—Femininity Index; UAI-Uncertainty Avoidance Index; TOI-Term Orientation Index; IRI-Indulgence Restraint Index. ${ }^{* *}$ Correlation is significant at the 0.01 level; * Correlation is significant at the 0.05 level.

Regarding TOI and IRI, the results in Table 5 show that no significant correlations were found among the applied variables.

\section{Discussion}

This study presents recent sociodemographic information about beekeepers and beekeeping activities in seven European countries (Estonia, Croatia, Finland, Italy, Norway, Portugal and Spain). Among the seven countries, there were significant differences regarding age, sex, income, experience in beekeeping activities, fraction done by unpaid people and education level.

The participants in this study were mostly over 31 years of age, with a significant percentage being over 60 years old. Italy was the country with the youngest participants $(31.25 \%)$, while Norway had the oldest ones (36.6\%).

Information about European beekeepers is sparse. However, the Report on Prospects and Challenges for the EU Apiculture Sector [26], produced by the Committee on Agriculture and Rural Development, notes a particularly serious ageing problem in this sector, with only a small percentage of beekeepers in EU being aged under 50. In fact, as in our study, in the EPILOBEE project, only $4.35 \%$ of the beekeepers were less than 30 years old, and $23.1 \%$ were between 31 and 45 [27]. The ageing of the general population is a common problem in all European countries. Additionally, young people are not widely attracted to agriculture and agrarian activities like beekeeping. Therefore, it is urgent take measures to attract young people to this sector.

There is also very limited information about women beekeepers. Even with the numbers of new women beekeepers growing all over the world, they are always less represented than men [28-32]. In our study, women were also underrepresented, with Italy being the country with the highest percentage of women (37.5\%) and Spain the country with the lowest $(10 \%)$. Beekeeping is an activity mainly carried out by men, even though it has the potential to contribute to the empowerment of rural women, reinforcing their role 
in agriculture [33]. This is an activity that can be easily adjusted to the multifunctional role of rural women while, at the same time, providing an additional source of income.

The average annual income among beekeepers was lower than $50,000 €$ in all countries except Norway. More than $50 \%$ of the Italian and Croats reported earning less than $15,000 €$ per year, while more than $50 \%$ of Estonian, Finnish, Spanish and Portuguese participants reported earning between 15,000 $€$ and 50,000 $€$ per year. In Europe, beekeeping activities provide over 620,000 EU citizens with their main income or additional earnings [34].

Regarding educational level, most of the participants had higher or secondary education. In Finland and Norway, the level of education among beekeepers was highest. This was as expected, as the national levels of education are higher in these two nations (over 38\%) (https:/ / www.statista.com/statistics/1084737/eu-28-adults-with-tertiary-educationattainment/, accessed on 21 October 2021).

Most of the participants had more than five years of experience in beekeeping (over $60 \%$ in all countries) with the exception of Italy, where only $42 \%$ reported having more than five years of experience. This is possibly related to the fact that Italy was the country with the highest proportion of youngest participants (31.3\%).

According to the EU [35], in 2019, the total number of beekeepers in Europe was over 600,000 with Italy being the country, among the countries included in this study, with the highest percentage (8.3\%) of European beekeepers, followed by Spain (3.9\%) which was also the country with the highest percentage of beehives (16.8\%). More than $70 \%$ of respondents had up to 150 colonies. Portugal was the country in which the most participants had apiaries with more than 151 colonies (30.2\%), but this result did not correspond to the real beekeeping scenario in the country, given that the percentage of beekeepers with more than 150 colonies was, in 2018, only 10.9\% [36,37]. Portugal had also the highest average number of colonies per beekeeper (229), that is over the reported average number of colonies per beekeeper (67.9 in 2018) [35].

In all the countries, most of the beekeepers were still hobbyist or nonprofessional beekeepers, which is in line with the results obtained. In fact, the beekeeping activity is usually not the main source of income across European countries [38]. Norway was the country where more participants were only beekeepers. Once beekeeping is an activity that provides, on average, low annual income, it is natural beekeepers had another activity besides beekeeping, being mainly hobbyist or nonprofessional beekeepers.

About one third of the participants referred to work alone and only $8 \%$ hire other people to work with them. This is consistent with the percentage of professional beekeepers, both in our sample ( $14 \%$ when considering professional beekeepers with more than 150 colonies), and in Europe (4\% of professional beekeepers) [39].

As mentioned before, Hofstede's cultural dimensions offers a framework for crosscultural communication and analysis. It allows us to understand the effects of a society's culture on the values of its members, and how these values relate to behavior, using a structure derived from factor analysis, based on six dimensions previously described.

Power Distance Index expresses how the less powerful members of a society accept and expect a certain inequality of power, or in other words how the society handles inequalities among people [14]. In our sample, the Hofstede analysis shows that the countries with high Power Distance Index (PDI), the beekeepers had lower values of annual income and low educational level. Croatia, Portugal and Spain were the countries with high PDI while Norway, Finland and Estonia had low PDI values and higher values of annual income and higher education level. The members of societies with a high PDI tend not to question those who are at higher levels of power. In addition, they expect that more powerful members might serve as guides for their work. In cultures with a low PDI, the power is equally distributed among its members, and they move towards a higher status (through education, employment, income, etc.). It is therefore not surprising that the countries with high PDI values are the ones with the lowest level of education as well as the lower annual income. 
In individualistic societies, where the Individualism Collectivism Index (ICI) is lower, members tend to make decisions in an independent way and care about themselves and their close family, while in collectivist societies (with higher ICI), group ties are strong and the family includes the entire family extension (uncles, aunts, cousins, etc.) [14]. In this case, we found no significant variables associated with this cross-cultural dimension. Nevertheless, it seems that women tend to be less individualist than man. Other studies have found a similar trend, with women being generally more collectivist than their males' counterparts, especially among small-holder businesses [40]. Even recognizing that through cooperation, the return from the beekeeping activity may increase, there are still numerous beekeepers that prefer to work alone and doesn't join any kind of cooperative or association among peers [41].

The Masculinity Femininity Index (MFI) refers to gender effects in the societies, with low scores (Feminine societies) on the dimension meaning that the dominant values are caring for others and quality of life as opposed to high scores (masculine societies) where the societies are driven by competition, achievement and success [14]. In societies with high masculinity, people are driven by competition and results, so people tend to be assertive and centered on material success. On the other hand, in societies with low masculinity or characteristics of femininity, people are focused on building good relationships and ensuring better quality of life for everyone. It is not so important to be the best, as long as everyone is happy. Among the groups of beekeepers at study, we found strong correlations between MFI, age, income and education. Norway was the most Feminine society, with older and more educated beekeepers and with higher values of annual income. On the opposite side, Italy presented a higher value of masculinity, and also younger beekeepers with lower income values. In fact, Norway has been a leading country implementing institutional solutions to attain equality between men and women, positioning the country as a world leader in gender equality [42-44]

The Uncertainty Aversion Index (UAI) was strongly related with education and professionalism (number of colonies). In fact, countries with high UAI (Portugal, Spain, Croatia, Italy, Estonia e Finland) had more colonies and low educational level. The Uncertainty Aversion Index explains how members of a society feel when dealing with unknown situations [14]. In cultures with strong UAI, people tend to avoid risks and unexpected situations, because they create great anxiety and stress, preferring to face predictable or controlled situations. Contrarily, members of a culture with a weak UAI tend to be more tolerant towards what they cannot control. Uncertainty is accepted as part of life and people are generally more relaxed and flexible when they must face unknown situations. Rossi and Sekhposyan [45] presented a macroeconomic forecast distribution of uncertainty among European countries, showing that Italy, Spain and Portugal were more avert to uncertainty specially during the sovereign debt crisis, while for the same period Netherlands was always more tolerant to uncertainty [45]. In fact, Norwegian beekeepers seems to be more resilient in face of uncertainty, which is probably related with their level of education (that is higher). Also, Norway is the country with a smaller number of colonies per beekeeper and with a higher number of nonprofessional beekeepers, thus resulting in beekeepers that are probably not so dependent on the revenue from the activity and more prepared to take risks.

Both for the Term Orientation Index (TOI) and Indulgence Restraint Index (IRI), we could not find significant correlations among the variables at study and the indexes. In fact, the TOI index refers to the links with the past while dealing with the challenges of the present and the future, and none of the variables at study shows a trend towards the past or the future of the beekeepers and its activities.

The Indulgence Restraint Index analyses the importance of happiness and control of life. Societies with high complacency (high IRI) allow people to freely satisfy their basic human needs and desires, especially those related to enjoying life and having fun. In societies with a high rate of repression (low IRI), people suppress their impulses through 
restrictive social norms. These societies have a high consideration for moral discipline and people tend to be more pessimistic [14].

\section{Conclusions}

The results of this research allow us to draw a few conclusions about the characteristic of beekeeping activities in seven European countries. First of all, there are significant differences among sociodemographic variables and experience in beekeeping between countries.

Most beekeepers who answered the questionnaire were over 31 years old, and were men, with Italy being the country with the highest percentage of young, female beekeepers. Norway was the only country with an average annual income over $50,000 €$, while respondents from Italy and Croatia generally had incomes below 15,000 €. Most participants had secondary or higher education levels, with those from Norway and Finland having the highest level of education. About $90 \%$ of participants had up to 150 colonies and were mainly nonprofessionals or hobbyists; about one quarter were certified as organic $(n=74)$. Members of the family and friends play an important role in beekeeping activities, and just $2 \%$ of respondents reported having hired workers (most commonly in Italy). The main product of the hive is honey (75-98\%), followed by wax (15-45\%) and colonies (13-32\%); these values varied for each country in the study. In most cases, the average honey production per hive was $21-50 \mathrm{~kg}$, per season, with Estonia and Finland reporting the highest yields (38 kg and $36 \mathrm{~kg}$, respectively) and Portugal the lowest $(13.7 \mathrm{Kg}$ ).

Relating these values with the cross-cultural dimensions defined by Hofstede, we found no variables to be significantly associated with the Individualism Collectivism Index (ICI), Term Orientation Index (TOI) or Indulgence Restraint Index (IRI). However, in countries with a high Power Distance Index (PDI), beekeepers had lower annual income and educational level, e.g., in Croatia, Portugal and Spain, meaning that they are more available to accept and expect a certain inequality of power among society members. Furthermore, we found a strong correlation between the Masculinity Femininity Index (MFI), age, income and education, with Norway being the most Feminine society, i.e., with more educated and older beekeepers. The Uncertainty Aversion Index (UAI) was strongly related with education and number of colonies, with high values for six countries but not for Norway, meaning that Norwegian beekeepers seem to be more resilient to uncertainly, i.e., they are more inclined to take risks when faced with unexpected situations.

Education and training contribute to beekeepers' incomes, serving to balance the distribution of power among members of the society, and thus increasing their PDI. So, beekeeping training is important to reinforce the sector and its sustainability, especially in Croatia, Portugal, Spain, and Italy. Long-term oriented societies (i.e., with high TOI values) encourage people to invest in the future through education and economic development, so we might consider that support through education and incentives to innovate will empower beekeepers. Finally, this work contributes to our understanding of how beekeeping activities are developed, and the roles played by stakeholders in different countries in the European Union, considering different socio-economic and cultural contexts, as well as the promotion of innovation in beekeeping and the transfer of knowledge and good practices.

The present work had some limitations, namely, the number of respondents from each country was neither equal nor proportional due to difficulties in recruiting participants. Also, the distribution of sociodemographic groups was not the same among countries, and it was also not possible to recruit the same number of participants from different activities in the beekeeping sector. Still, even with these limitations, this work provides new insights into the characterization and understanding of the beekeeping sector in some countries, and will serve as a support for future research in this area. 
Author Contributions: Conceptualization, R.P.F.G.; methodology, R.P.F.G. and J.O.; software, R.P.F.G.; validation, R.P.F.G.; formal analysis, R.P.F.G.; investigation, R.P.F.G., S.M., C.A.C., H.E.C., B.D., R.R., R.K., L.T., S.B., E.B., I.S., M.O., C.C. and J.O.; resources, C.A.C.; data curation, R.P.F.G.; writingoriginal draft preparation, D.T.C., P.C., J.O., C.C. and R.P.F.G.; writing-review and editing, R.P.F.G.; visualization, R.P.F.G.; supervision, R.P.F.G.; project administration, C.A.C.; funding acquisition, C.A.C. All authors have read and agreed to the published version of the manuscript.

Funding: This research was funded by project beeB-Foster for beekeeping bridges through innovative and participative training (ref. 2019-1-PT01-KA202-060782). The APC was funded by FCTFoundation for Science and Technology, I.P., within the scope of the project Ref. UIDB/00681/2020.

Institutional Review Board Statement: This research was implemented taking care to ensure all ethical standards and followed the guidelines of the Declaration of Helsinki.

Informed Consent Statement: Informed consent was obtained from all subjects involved in the study.

Data Availability Statement: Data are available from the first author (R.P.F.G.) upon reasonable request.

Acknowledgments: This work was developed under project beeB-Foster for beekeeping bridges through innovative and participative training (ref. 2019-1-PT01-KA202-060782). The authors would also like to acknowledge support from the FCT-Foundation for Science and Technology, I.P., within the scope of the project Ref. UIDB/00681/2020, as well as the CERNAS Research Centre and the Polytechnic Institute of Viseu.

Conflicts of Interest: The authors declare no conflict of interest.

\section{References}

1. Brodschneider, R.; Brus, J.; Danihlík, J. Comparison of Apiculture and Winter Mortality of Honey Bee Colonies (Apis Mellifera) in Austria and Czechia. Agric. Ecosyst. Environ. 2019, 274, 24-32. [CrossRef]

2. Uchiyama, Y.; Matsuoka, H.; Kohsaka, R. Apiculture Knowledge Transmission in a Changing World: Can Family-Owned Knowledge Be Opened? J. Ethn. Foods 2017, 4, 262-267. [CrossRef]

3. Fels, D.I.; Blackler, A.; Cook, D.; Foth, M. Ergonomics in Apiculture: A Case Study Based on Inspecting Movable Frame Hives for Healthy Bee Activities. Heliyon 2019, 5, e01973. [CrossRef]

4. Popescu, C.R.G.; Popescu, G.N. The Social, Economic, and Environmental Impact of Ecological Beekeeping in Romania in Agrifood Economics and Sustainable Development in Contemporary Society; IGI Global: Hershey, PA, USA, 2019; pp. 75-96.

5. Andrews, E. 'The Main Objection to Numerous Small Bee Keepers': Biosecurity and the Professionalization of Beekeeping. J. Hist. Geogr. 2020, 67, 81-90. [CrossRef]

6. Paris, E.H.; Peraza Lope, C.; Masson, M.A.; Delgado Kú, P.C.; Escamilla Ojeda, B.C. The Organization of Stingless Beekeeping (Meliponiculture) at Mayapán, Yucatan, Mexico. J. Anthropol. Archaeol. 2018, 52, 1-22. [CrossRef]

7. Wagner, K.; Meilby, H.; Cross, P. Sticky Business-Why Do Beekeepers Keep Bees and What Makes Them Successful in Tanzania? J. Rural Stud. 2019, 66, 52-66. [CrossRef]

8. Devkota, K. Beekeeping: Sustainable Livelihoods and Agriculture Production in Nepal. In Modern Beekeeping—Bases for Sustainable Production; Ranz, R.E.R., Ed.; IntechOpen: London, UK, 2020; 11p, ISBN 978-1-83880-156-4.

9. Fedoriak, M.; Kulmanov, O.; Zhuk, A.; Shkrobanets, O.; Tymchuk, K.; Moskalyk, G.; Olendr, T.; Yamelynets, T.; Angelstam, P. Stakeholders' Views on Sustaining Honey Bee Health and Beekeeping: The Roles of Ecological and Social System Drivers. Landsc. Ecol. 2021, 36, 763-783. [CrossRef]

10. Lourenço, M.S.M.; de O Cabral, J.E. Apicultura e Sustentabilidade: Visão dos Apicultores de Sobral (CE). Rev. Agro. Amb. 2016, 9, 93. [CrossRef]

11. Khan, A.S.; de Matos, V.D.; Lima, P.V.P.S. Desempenho da apicultura no estado do Ceará: Competitividade, nível tecnológico e fatores condicionantes. Rev. Econ. Sociol. Rural 2009, 47, 651-676. [CrossRef]

12. FAO Journée Mondiale Des Abeilles: La Production Apicole et Les Bonnes Pratiques Adoptées Par Des Apiculteurs Pour Soutenir Leurs Moyens d'existence. Available online: http://www.fao.org/africa/news/detail-news/en/c/1278688/ (accessed on 24 May 2021).

13. FAO Organização Das Nações Unidas Para Agricultura e Alimentação: Dia Internacional Da Abelhas: Polinizadoras Essenciais Para o Futuro Dos Alimentos I FAO No Brasil I Food and Agriculture Organization of the United Nations. Available online: http:/ / www.fao.org/brasil/noticias/detail-events/pt/c/1195001/ (accessed on 25 May 2021).

14. Hofstede, G.; Hofstede, G.J;; Minkov, M. Cultures and Organizations—Software of the Mind, 3rd ed.; McGraw-Hill: New York, NY, USA, 2010.

15. Hofstede, G. Culture's Consequences-Comparing Values, Behaviors, Institutions and Organizations Across Nations, 2nd ed.; SAGE Publishing-Academic Books: Thousand Oaks, CA, USA, 2001. 
16. Djekic, I.; Kane, K.; Tomic, N.; Kalogianni, E.; Rocha, A.; Zamioudi, L.; Pacheco, R. Cross-Cultural Consumer Perceptions of Service Quality in Restaurants. Nutr. Food Sci. 2016, 46, 827-843. [CrossRef]

17. Nyarugwe, S.P.; Linnemann, A.R.; Ren, Y.; Bakker, E.-J.; Kussaga, J.B.; Watson, D.; Fogliano, V.; Luning, P.A. An Intercontinental Analysis of Food Safety Culture in View of Food Safety Governance and National Values. Food Control 2020, 111, 107075. [CrossRef]

18. Huang, S.S.; Crotts, J. Relationships between Hofstede's Cultural Dimensions and Tourist Satisfaction: A Cross-Country CrossSample Examination. Tour. Manag. 2019, 72, 232-241. [CrossRef]

19. Kang, D.S.; Mastin, T. How Cultural Difference Affects International Tourism Public Relations Websites: A Comparative Analysis Using Hofstede's Cultural Dimensions. Public Relat. Rev. 2008, 34, 54-56. [CrossRef]

20. Cronjé, J.C. Using Hofstede's Cultural Dimensions to Interpret Cross-Cultural Blended Teaching and Learning. Comput. Educ. 2011, 56, 596-603. [CrossRef]

21. Thowfeek, M.H.; Jaafar, A. Instructors' View about Implementation of E-Learning System: An Analysis Based on Hofstede's Cultural Dimensions. Procedia Soc. Behav. Sci. 2012, 65, 961-967. [CrossRef]

22. Witten, R.; Witte, J. Statistics, 9th ed.; Wiley: Hoboken, NJ, USA, 2009.

23. Maroco, J. Análise Estatística Com o SPSS Statistics, 5th ed.; ReportNumber: Sintra, Portugal, 2012.

24. Pestana, M.H.; Gageiro, J.N. Análise de Dados Para Ciências Sociais-A Complementaridade Do SPSS, 6th ed.; Edições Sílabo: Lisboa, Portugal, 2014.

25. Hofstede, G. Compare Countries-Hofstede Insights. Available online: https://www.hofstede-insights.com/product/comparecountries / (accessed on 21 May 2021).

26. European Parliament. Prospects and Challenges for the EU Apiculture Sector; European Parliament: Brussels, Belgium, 2018. Available online: https://www.europarl.europa.eu/doceo/document/TA-8-2018-0057_EN.html/ (accessed on 21 October 2021).

27. Jacques, A.; Laurent, M.; Ribiere-Chabert, M.; Saussac, M.; Bougeard, S.; Hendrikx, P.; Chauzat, M.-P. Statistical Analysis on the EPILOBEE Dataset: Explanatory Variables Related to Honeybee Colony Mortality in EU during a 2 Year Survey. EFSA Supporting Publ. 2016, EN-883, 228. [CrossRef]

28. Dassou, A.G.; Ogouchoro, D.; Vodouhe, F.G.; Dassou, H.G.; Dansi, A.; Tixier, P. Ethnoapicultural Investigation to Improve Conservation Status of Threatened Melliferous Agroforestry Species with High Medicinal and Food Values in Benin. Agroforest Syst. 2020, 94, 539-553. [CrossRef]

29. Olana, T.; Demrew, Z. The Role of Women in Beekeeping Activities and the Contribution of Bee-Wax and Honey Production for Livelihood Improvement. Livest. Res. Rural Dev. 2018, 30, 118.

30. Mburu, P.D.M.; Affognon, H.; Irungu, P.; Mburu, J.; Raina, S. Gender Roles and Constraints in Beekeeping: A Case from Kitui County, Kenya. Bee World 2017, 94, 54-59. [CrossRef]

31. Horn, T. Beeconomy: What Women and Bees Can Teach Us About Local Trade and the Global Market; University Press of Kentucky: Lexington, KY, USA, 2012; ISBN 978-0-8131-3435-2.

32. Gross, B. Women in Beekeeping: Impacts of a Beekeeper Educational Program. Master's Thesis, University of Nebraska-Lincoln, St, Lincoln, NE, USA, 2020.

33. Pocol, C.B.; McDonough, M. Women, Apiculture and Development: Evaluating the Impact of a Beekeeping Project on Rural Women's Livelihoods. Bull. Univ. Agric. Sci. Vet. Med. Cluj-Napoca. Hortic. 2015, 72, 487-492. [CrossRef]

34. Erdős, N. Report on Prospects and Challenges for the EU Apiculture Sector; Committee on Agriculture and Rural Development: Brussels, Belgium, 2018; p. 32.

35. European Commission. National Apiculture Programmes 2020-2022. EU Beekeeping Sector. Available online: https://ec. europa.eu/info/sites/default/files/food-farming-fisheries/animals_and_animal_products/documents/honey-apicultureprogrammes-overview-2020-2022.pdf (accessed on 10 November 2021).

36. GPP. Programa Apícola Nacional 2017-2019 (Portugal); Gabinete de Planeamento, Políticas e Administração Geral: Lisboa, Portugal, 2016; p. 99.

37. Portugal: National Apiculture Programme 2020-22. Available online: https:/ / ec.europa.eu/info/system/files/food-farmingfisheries/animals_and_animal_products/documents/nap-pt_pt.pdf (accessed on 10 November 2021).

38. Chauzat, M.-P.; Laura, C.; Roy, L.; FRANCO, S.; Hendrikx, P.; Ribière-Chabert, M. Demographics of the European Apicultural Industry. PLoS ONE 2013, 8, e79018. [CrossRef]

39. Rossi, S. The EU's Beekeeping Sector-At a Glance 2017; European Parliamentary Research Service: Brussels, Belgium, 2017. Available online: https:/ / www.europarl.europa.eu/RegData/etudes/ATAG/2017/608786/EPRS_ATA(2017)608786_EN.pdf (accessed on 10 November 2021).

40. Zeffane, R. Gender, Individualism-Collectivism and Individuals' Propensity to Trust: A Comparative Exploratory Study. J. Manag. Organ. 2020, 26, 445-459. [CrossRef]

41. Frick, M.; Grgić, Z.; Franić, R.; Štefanić, I.; Kezić, N. Cooperative Business Potential for Beekeepers in Croatia. J. Apic. Res. 2006, 45, 223-229. [CrossRef]

42. Tomczak, D.A. Gender Equality Policies and Their Outcomes in Norway. Zarz. Publiczne 2016, 4, 379-391. [CrossRef]

43. Hutt, R. These 10 Countries Are Closest to Achieving Gender Equality. Available online: https://www.weforum.org/agenda/20 19/12/gender-gap-equality-women-parity-countries/ (accessed on 28 September 2021). 
44. Statistics Norway Norway_World Leader in Gender Equality. Available online: https://www.ssb.no/en/befolkning/artiklerog-publikasjoner/norway-world-leader-in-gender-equality (accessed on 28 September 2021).

45. Rossi, B.; Sekhposyan, T. Macroeconomic Uncertainty Indices for the Euro Area and Its Individual Member Countries. Empir. Econ. 2017, 53, 41-62. [CrossRef] 